\title{
PROGNOSTIC EVALUATION OF THE IMPACT OF RESTRICTED HORIZON VISIBILITY ON THE ACCURACY OF POSITION (COORDINATES) OBTAINED WITH GNSS BASED ON EMPIRICAL DATA
}

\author{
Oleksandr YANCHUK ${ }^{\mathbb{D}}$, Roman SHULGAN $\mathbb{D}^{*}$ \\ Educational and Scientific Institute Agroecology and Land Management, \\ National University of Water and Environmental Engineering, Rivne, Ukraine
}

Received 13 December 2019; accepted 03 June 2020

\begin{abstract}
In this research, the practical check of regression equation to calculate the prognostic root mean square error (RMSE) of the final point position of the base line in relation to the initial one has been executed. For the investigation, experimental data from three satellite receivers within two days on 5 points have been used. According to the received results, the regression equation to calculate the RMSE of spatial, planned and height position of the final point of the base line in relation to the initial value has been made. These equations allow executing the prognostic evaluation of accuracy for conducting satellite calculations based on data about available obstacles. The dependencies received for the duration of observations sessions for 1 hour, the vectors with the length of $4 \mathrm{~km}$, and the coefficient value of openness from 5.17 to 10.31 have been presented.
\end{abstract}

Keywords: GPS, GNSS, regression equation, satellite observations, limited horizon visibility, accuracy, permanent station, electronic total station, root mean square error (RMSE).

\section{Introduction}

Geodesic evaluations with the help of global navigation satellite systems (GNSS) have come through the first steps to their mass use in all spheres of human activity.

However, one of the limiting factors to use GNSS receivers is the obstacles, which close satellite visibility on the horizon. Even using the latest models of receivers, which support several satellite systems (GPS, GNSS, and Galileo), do not guarantee the possibility of work in the conditions of city construction or forest territory.

Using satellite technologies for observations in conditions of limited visibility of satellites demands investigating the impact of horizon closure related to accuracy for determining the location. Therefore, while conducting the investigation on territories with limited horizon visibility, an executor should make sure that within the radio visibility zone of the receiver there is going to be sufficient number of satellites for observations. For this matter, the preliminary planning of observation sessions using special software products, where the theory of satellite movements has been used, is being executed. During planning, the quantity and configuration of visible satellites, as well as the values of DOP coefficients in the determined timeframe on the set territory are being defined. However, these data do not allow setting the prognostic accuracy, which could be relied upon during observations. Therefore, it is necessary to apply the criteria, which enable the possibility of executing observations and their approximate accuracy.

\section{Analysis of research}

Limited horizon visibility impacts the effective activity of GPS-receivers, while limiting satellite visibility and significantly deteriorating the geometry of the satellite constellation. Except this, in such conditions, the errors related to outer conditions increase (ionosphere and troposphere delays, multi-ways of spreading signals, etc.). In such conditions, to successfully apply satellite technologies, the big importance is related to organizing and initial planning of field activities and choosing the methods and means for observations. With the help of successful selection of observations' means and instrumental enhancements, errors made by outer conditions could be compensated in some way.

*Corresponding author. E-mail: r.b.shulhan@nuwm.edu.ua 
Analyzing the literary sources related to this issue, several variants of dealing with the limited horizon visibility could be outlined. One of them is associated with increasing the antenna height. For this, telescope marks, which allow increasing the height of the antenna and increasing horizon visibility, have been proposed (Antonovich, 2005). For example, the geodetic service of Sweden has developed the 30-metre mast, which should be installed vertically above the point with the help of two theodolites (Kijewski-Correa \& Kareem, 2003). The disadvantage of this method is related to increasing the errors of centring, measuring the antenna height, and associated complexity of providing its verticality.

By locating the receivers not far from the obstacles, the errors of multi-ways for spreading a signal increase (Bida, 2015). For the elimination of additional resisted waves GPS-antennas should be used, which are sensitive to the polarization of the signal or equipped with a special protective choke ring.

The stability of eccentricity of the antenna phase centre also depends on the additional resistance of satellite signals and the impact of other noise. It should be considered with the means of inputting corrections in the measurement based on experimental investigations (Bida, 2015).

Also, the attempts of solving the problems in the way of developing the methods, which are able to calculate the navigational location based on 2 (Dai et al., 2002) - 3 (Santerre \& Boulianne, 1995) of visible satellites should be noted. This is achieved using high-sensitive receivers registering the weakened signals from satellites even indoor. However, most frequently, in practice, the problem of insufficient satellites visibility in the conditions of urban construction is being solved by setting points of GPS-observation on the most open territory, i.e., as a rule, on the roofs of a house (Fouque \& Bonnifait, 2010).

To calculate the prognostic accuracy evaluation, regression equations are being used. They are indicated by manufacturers in the instructions of device exploitation. However, such equations, as a rule, consider the dependency of accuracy observations only from the length of observations vector. In the meantime, the important factors that impact the accuracy of evaluations are the duration of a session (Baran \& Chornokin, 2004; Tretyak \& Shushkova, 2001; Tretyak, 2004; Kostetska et al., 2005), as well as quantity and configuration of observed satellites (Ohrimchuk et al., 2011; Gritsyuk \& Tretyak, 2007; Chernyaga \& Yanchuk, 2012; Yanchuk, 2010).

A significant amount of investigations in this direction have been executed under the guidance of Professor Tretyak K. R. (Gritsyuk \& Tretyak, 2007; Tretyak \& Shushkova, 2001; Tretyak, 2004). Particularly, based on experimental calculations, the dependency of accuracy evaluation of vertical composite vectors being related to their length $\mathrm{L}$ (within $2-10 \mathrm{~km}$ ) and the duration of observation $\mathrm{t}$ (within $10 \mathrm{~min}$ to 2 hours) on open territory has been found:

$$
m_{\Delta h}=(2.59 \pm 0.34) \cdot L-(0.50 \pm 0.37) \cdot L \cdot t .
$$

In the research (Gritsyuk \& Tretyak, 2007), the experimentally received dependencies of accuracy of calculated excesses from the minimal height of satellites above the horizon $a$ (within $5-25^{\circ}$, with the step $5^{\circ}$ ), the duration of observations $t$ (0.1-10 hour), and the vector length $L$ $(1-10 \mathrm{~km})$ have been provided.

$$
\begin{aligned}
& m_{\Delta h}=\left[\left(-0.0025 \times L_{(\mathrm{km})}+0.0146\right) \times t_{(h)}+0.15\right] \times \\
& \alpha_{(\mathrm{deg})}+5_{(\mathrm{mm})} ; \\
& m_{\Delta h}=\left[\left(0.00086 \times L_{(\mathrm{km})}-0.0246\right) \times t_{(\mathrm{h})}+0.44\right] \times \\
& \alpha_{(\mathrm{deg})}+5_{(\mathrm{mm})} .
\end{aligned}
$$

The dependency (2), which has been received before, did not consider the results of calculations executed with the minimal angle of the satellites height $\left(5^{\circ}\right)$, the vertical component of eccentricity of antenna phase centres, and weights of calculation.

Ohrimchuk, Chernyaga, and Yanchuk (2011) proposed criterion which helps to evaluate the impact of duration of satellite visibility in the specific sector of celestial vault and other obstacles on the accuracy of observation results.

In the results of investigations, the coefficient of horizon openness $k_{\text {open }}$, which could be calculated according to the following formula, has been offered by the authors:

$$
k_{\text {open }}=\sum_{i=1}^{n} p_{\text {open }}^{i}=\sum_{i=1}^{n}\left(p_{d u r}^{i} \cdot \sin Z_{i}\right)
$$

where $i=\overline{1, n}, n$ - number of sectors dividing the horizon; $Z$ - zenith distance of the horizon part that is free of obstacles in the $i$-sector; $P_{\text {open. }}$ - weight of horizon openness in each sector; $P_{d u r}$. - weight of duration of satellites presence in the sector.

Based on the proposed coefficient, the regression equations to calculate the RMSE of spatial $m_{\text {spat, }}$ planned $m_{\text {plan, }}$ and height $m_{\text {height }}$ location of the final point of the base line according to the initial one has been received:

$$
\begin{aligned}
& m_{\text {plan }}=(23.85 \pm 2.07)-(5.94 \pm 1.57) \cdot t- \\
& (1.49 \pm 0.21) \cdot k_{\text {open }}+(0.46 \pm 0.16) \cdot t \cdot k_{\text {open }}, m ; \\
& m_{\text {height }}=(25.43 \pm 1.14)-(1.59 \pm 0.35) \cdot t- \\
& (1.41 \pm 0.11) \cdot k_{\text {open }}, m ; \\
& m_{\text {spat }}=(35.62 \pm 2.27)-(5.33 \pm 1.72) \cdot t- \\
& (2.09 \pm 0.23) \cdot k_{\text {open }}+(0.33 \pm 0.17) \cdot t \cdot k_{\text {open }}, m .
\end{aligned}
$$

Equations (5)-(7) have been derived for the duration of observation sessions from 0.5 to 2 hours, the lengths of base lines from 4 to $7 \mathrm{~km}$, and $k_{\text {open }}$ from 5.86 to 12.05 . The accuracy of approximation is $2.5 \mathrm{~mm}$ for expression (5) and $2.7 \mathrm{~mm}$ for expressions (6) and (7). Analyzing the received coefficient values, it should be noted that they correspond to the accepted concept of the factors impact. It means that the negative values of coefficients in the equations (5), (6), and (7) near the variables $t$ and $k_{\text {open }}$ mean that with the increase of observations the duration 
and the lesser amount of obstacles (the values $k_{\text {open }}$ increase), as well as the values of errors will be decreasing.

The received regression equations could be used on the stage of projecting of GPS-evaluations while selecting the location site of observations depending on the size of the open horizon part.

The disadvantage of received regression Equations (5)-(7) is that they have been derived based on the modeled data of obstacles to pass through the satellite signals and factually consider only the limit of satellites visibility. Therefore, with real observations, while considering other sources of errors, i.e. multi-ways, the delays of the signal, centring, and errors of determining coordinates will increase in relation to calculated ones. Thus, as it has been noted in Ohrimchuk et al. (2011), the received Equations (5)-(7) demand the check on experimental measurement.

\section{Research methods}

The aim of research lies in receiving the clarified regression equations for the prognostic evaluation of accuracy of satellite observations within the limited visibility of the horizon based on empirical data.

For the practical check of Equations (5)-(7) (Ohrimchuk et al., 2011), the data of practical observations described in the research have been used (Yanchuk et al., 2017).

In the experiment (Yanchuk et al., 2017), the GPS observation data of three satellite receivers within two days on 5 points have been used. One receiver is located in an area with open horizon visibility (the percentage of horizon closure is - 17\%), and the rest is - under buildings with various levels of horizon closure (the percent of horizon closure is from 37 to $60 \%$ ). The registration interval of observations was 1 second. While analyzing the observations, the data from two permanent stations in Rivne - RIVN and RVNE have been used. The distance to the activity region from the permanent station RIVN is nearly $4.7 \mathrm{~km}$, and from the station RVNE it is $3.6 \mathrm{~km}$. The duration of observations on various points had been from 5 to 12 hours.

While analyzing, the time intervals had been divided into hour sessions. To check the accuracy of received solutions, the comparison of decoupling increments with the etalon values had been executed (the balanced values from both permanent stations for the whole period of observations).

Additionally, using the preliminary planning, the optimal 1-hour sessions of observations on each point have been selected. The selection criterion of the optimal hour of observations was related to the values of DOP indicators. After that, the comparison of calculated gains from the optimal sessions of observations (selected from the preliminary planning) with the etalon values (the balanced values from both permanent stations for the whole period of observations) has been executed (Yanchuk et al., 2017).

\section{The results of the research}

While executing satellite observations not only the values of horizon size matters being free from obstacles, but also the horizon part, in which the obstacles are located. Therefore, to consider this fact in the research (Ohrimchuk et al., 2011), the criterion has been proposed, i.e. the coefficient of horizon openness $\mathrm{k}_{\text {open }}$, which is calculated according to Equation (4).

To consider the duration of satellite visibility in a particular sector of the horizon during the day, the weight of duration of satellite presence in the $i$-sector $p_{d u r}$, which is calculated by the following formula, should be determined:

$$
p_{d u r}^{i}=\frac{T_{\text {sect }}^{i}}{T_{\max }},
$$

where $p^{i}{ }_{d u r}$ - weight of duration of satellites in the i-sector; $T^{i}{ }_{\text {sect }}$ - duration of satellites presence in the $i$-sector, $\mathrm{min} /$ day; $T_{\max }-$ maximum value of duration of satellites presence in one of all sectors, $\mathrm{min} /$ day.

Based on Equation (4), the value of coefficient of horizon visibility for the investigated 5 points has been calculated. The sector size has been accepted as $10^{\circ}$. The minimum possible value of visibility coefficient upon such conditions is 0 by $Z=0^{\circ}$, and the maximum is 10.99 by $Z=90^{\circ}$. As for observations, it is not recommended to use signals from satellites close to the horizon, we have used a cut off angle of $15^{\circ}$. Therefore, the maximum "useful" coefficient value of visibility is 10.31 by $Z=75^{\circ}$. By the outlines of obstacles, the average zenith distance of horizon visibility for each sector has been determined. For 5 investigated points, the calculated coefficient values of visibility are located within 5.17 to 10.31 . For point 001 from closedness horizon $42 \% k_{\text {open }}$ is 7.74 , for point 002 with horizon closedness $50 \% k_{\text {open }}$ is 6.82 , point 003 with horizon closedness is $17 \%$, the openness coefficient corresponds to the value and is 10.31 , point 005 with closedness $37 \%$ is 8.46 , point 006 with horizon closedness $60 \%$ and $k_{o p e n}$ is 5.16 , and for point 007 with closedness horizon $50 \% k_{\text {open }}$ is 6.82 . The smallest value $k_{\text {open }}$ is on point 006 with the biggest percentage of horizon closedness, consequently, the biggest value $k_{\text {open }}$ is on the point 003 with the least horizon closedness.

To determine the prognostic accuracy of spatial, planned, and height location the regression Equations (5)-(7) have been used (Ohrimchuk et al., 2011). Their general appearance is described by the following function:

$$
m=a+b \cdot t+c \cdot k_{\text {open }}+d \cdot t \cdot k_{\text {open }},
$$

where $m$ - RMSE of the final point location of the base line related to the initial one in $\mathrm{mm} ; a, b, c, d$-permanent unknown coefficients; $t$ - duration of observations in hours.

Let's input into Equations (5)-(7) the values of calculated $k_{\text {open }}$ for the investigated points. The received results are provided in Table 1. 
Table 1. Received values of RMSE of spatial $m_{\text {spat }}$, planned $m_{\text {plan }}$ and height $m_{\text {height }}$ location of points

\begin{tabular}{|c|c|c|c|c|c|}
\hline $\begin{array}{c}\text { No. of } \\
\text { points }\end{array}$ & $\begin{array}{c}\text { Percen- } \\
\text { tage of } \\
\text { horizon } \\
\text { closed- } \\
\text { ness }\end{array}$ & $\begin{array}{c}\text { The coefficient } \\
\text { of horizon } \\
\text { openness } \\
k_{\text {open, }} \%\end{array}$ & $\begin{array}{c}m_{\text {plan }} \\
\mathrm{m}\end{array}$ & $\begin{array}{c}m_{\text {height }} \\
\mathrm{m}\end{array}$ & $\begin{array}{c}m_{\text {spat }} \\
\mathrm{m}\end{array}$ \\
\hline 1 & 42 & 7.74 & 0.0099 & 0.0129 & 0.0167 \\
\hline 2 & 50 & 6.82 & 0.0109 & 0.0142 & 0.0183 \\
\hline 3 & 17 & 10.31 & 0.0070 & 0.0089 & 0.0116 \\
\hline 5 & 37 & 8.46 & 0.0091 & 0.0119 & 0.0154 \\
\hline 6 & 60 & 5.16 & 0.0126 & 0.0166 & 0.0212 \\
\hline 7 & 50 & 6.82 & 0.0109 & 0.0142 & 0.0183 \\
\hline
\end{tabular}

Let us compare the received errors of experimental investigations without executing the preliminary planning of observations (they are provided in Yanchuk et al. (2017)) with the calculated values according to the Equations (5)(7) (Figures 1-3).

Comparing the received errors of experimental investigations with executing the preliminary planning of observations (they are provided in Yanchuk et al. (2017)) with the calculated values according to Equations (5)-(7) (Figures 4-6).

As it has been foreseen in the research (Ohrimchuk et al., 2011), the calculated prognostic values of accuracy appear to be overstated in comparison with practical results. Only the trend of results received considering the preliminary planning corresponds to the data received by the formulas of prognostic accuracy evaluation.

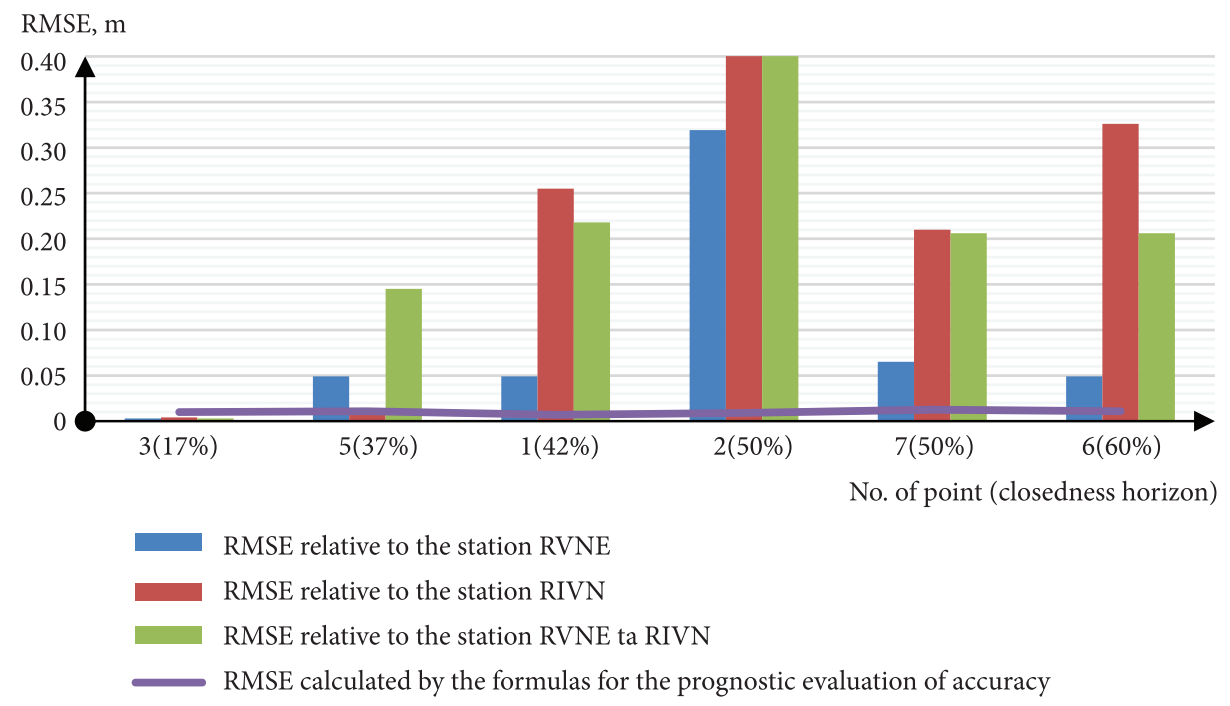

Figure 1. Comparison of RMSE of the planned location by the session duration for 1 hour without executing the preliminary planning and prognostic points of accuracy evaluation calculated by Equation (5)

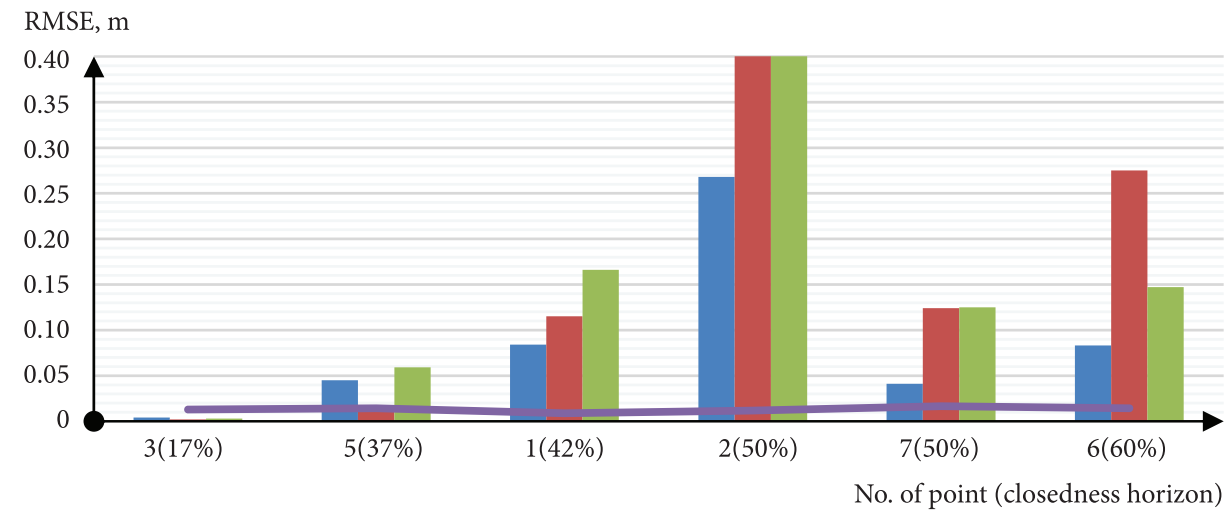

RMSE relative to the station RVNE

RMSE relative to the station RIVN

RMSE relative to the station RVNE ta RIVN

Figure 2. Comparison of RMSE of the height location by the session duration for 1 hour without executing the preliminary planning and prognostic points of accuracy evaluation calculated by Equation (6) 


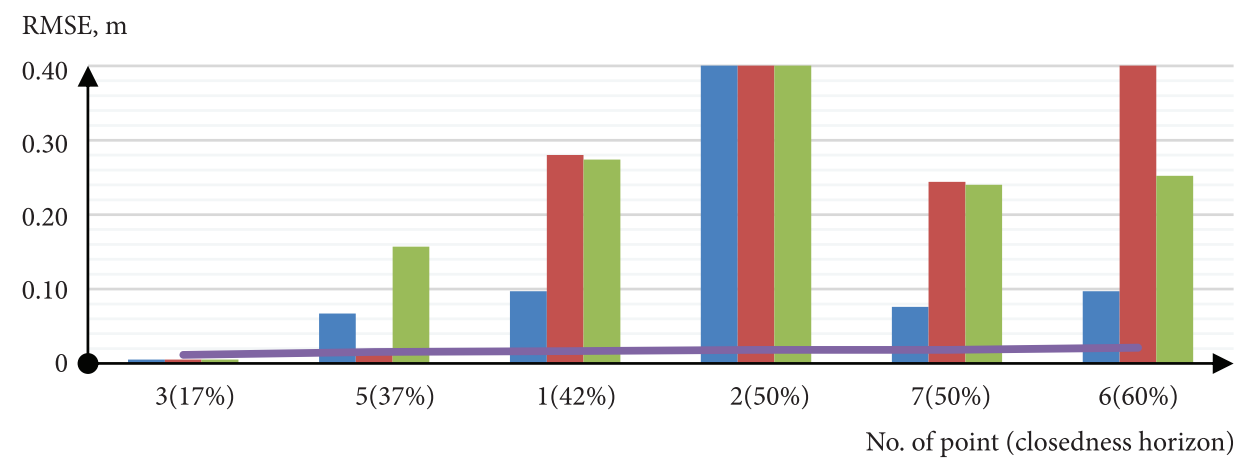

RMSE relative to the station RVNE

RMSE relative to the station RIVN

RMSE relative to the station RVNE ta RIVN

Figure 3. Comparison of RMSE of the spatial location by the session duration for 1 hour without executing the preliminary planning and prognostic points of accuracy evaluation calculated by Equation (7)

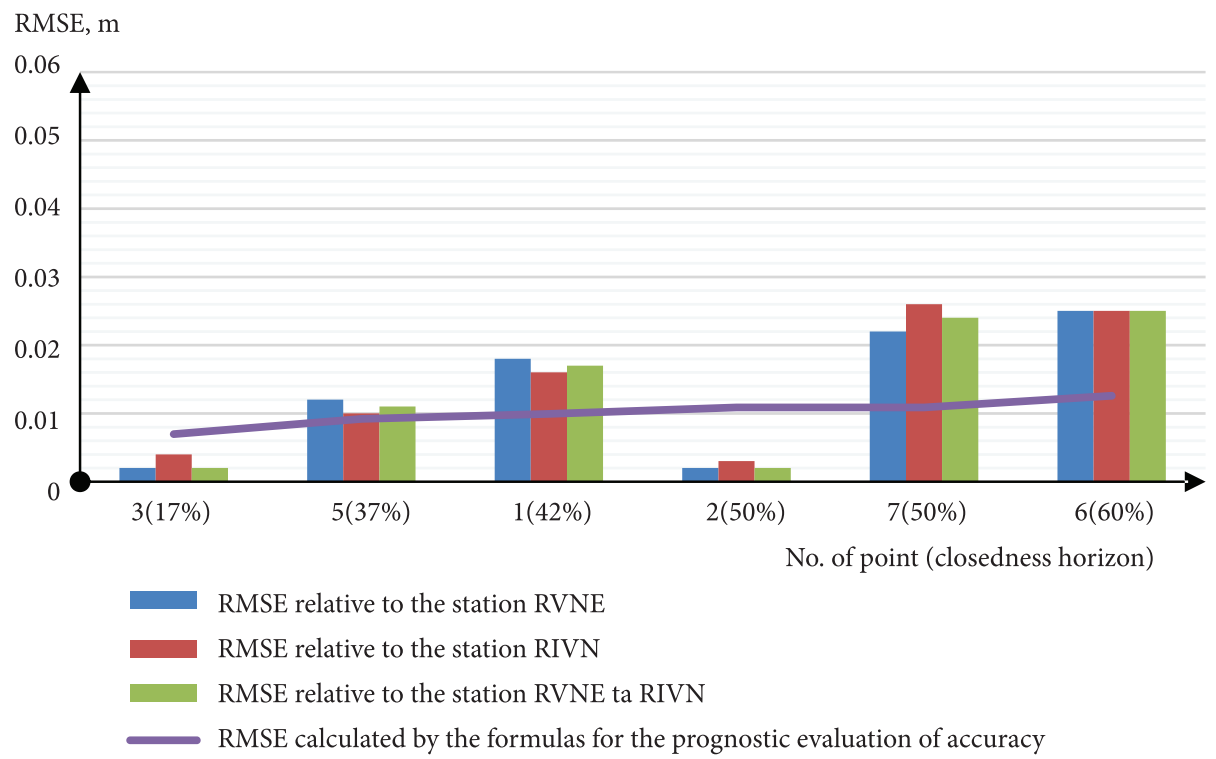

Figure 4. Comparison of RMSE of the planned location by the session duration for 1 hour with executing the preliminary planning and prognostic points of accuracy evaluation calculated by Equation (5)

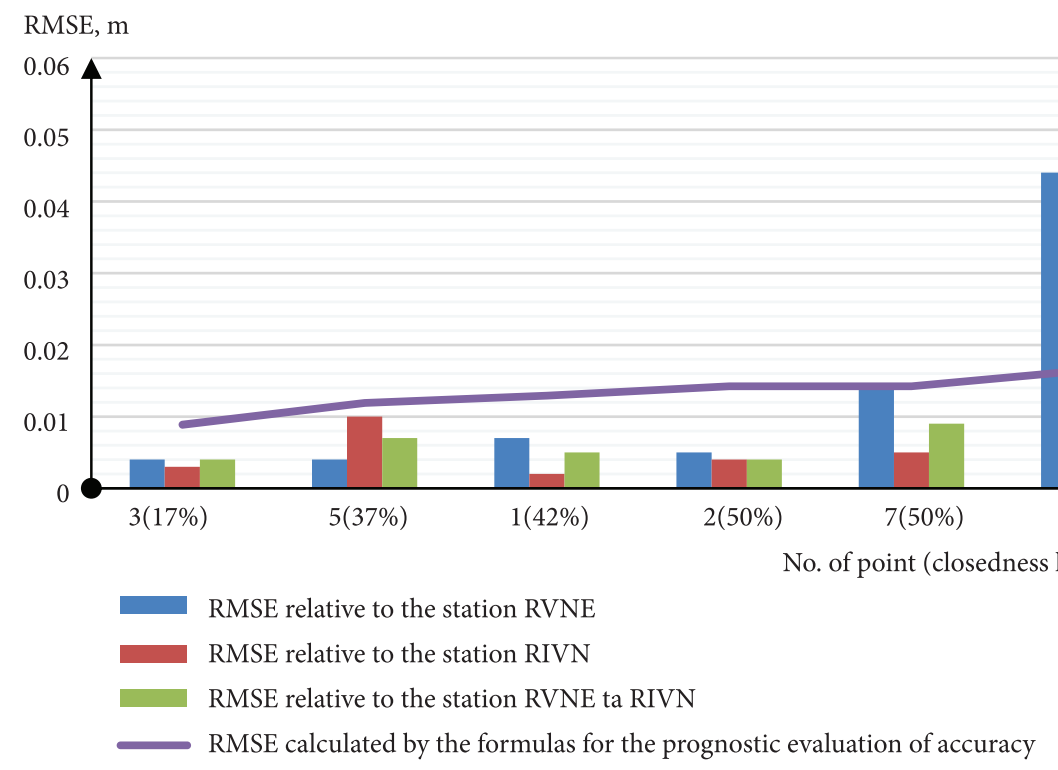

Figure 5. Comparison of RMSE of the height location by the session duration for 1 hour with executing the preliminary planning and prognostic points of accuracy evaluation calculated by Equation (6) 


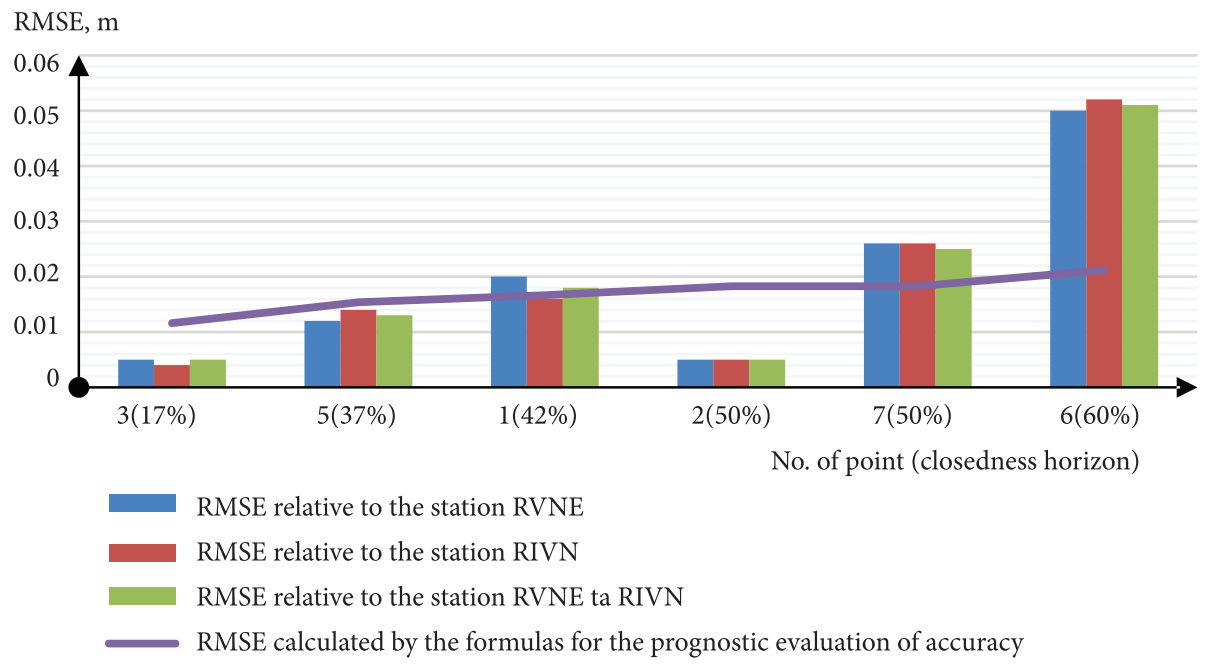

Figure 6. Comparison of RMSE of the spatial location by the session duration for 1 hour with executing the preliminary planning and prognostic points of accuracy evaluation calculated by Equation (7)

Therefore, let's enhance the regression equations of prognostic accuracy evaluation by considering the experimental results of observations. According to our results of evaluation, 159 equations of the type (9) for each researched dependency have been provided. As in our research the value of observations duration $t$ is permanent and equals 1 hour, the values of coefficients $b$ and $d$ are equal to 0 . Therefore, let's use the shortened type of representing regression equations:

$$
m=a+c \cdot k_{\text {open }} \text {. }
$$

As a result of calculations, the regression equations are:

$$
\begin{aligned}
& m_{\text {spat }}=(0.45 \pm 0.11)-(0.04 \pm 0.05) \cdot k_{\text {open }}, m ; \\
& m_{\text {plan }}=(0.32 \pm 0.09)-(0.03 \pm 0.005) \cdot k_{\text {open }}, m ; \\
& m_{\text {height }}=(0.18 \pm 0.07)-(0.017 \pm 0.005) \cdot k_{\text {open }}, m
\end{aligned}
$$

Equations (11)-(13) have been calculated for the duration of session observations for 1 hour, the lengths of base lines for $4 \mathrm{~km}$, and the coefficient of openness from 5.17 to 10.31 .

Let's compare the received errors of experimental investigations without executing the preliminary planning (provided in Yanchuk et al. (2017)) with the calculated prognostic values by the Equations (11)-(13) (Figures 7-9).

\section{Conclusions}

The value of criterion of horizon openness for the investigated points has been calculated. Moreover, the existing formulas for the prognostic evaluation of observation accuracy within the limited horizon visibility's conditions have been checked.

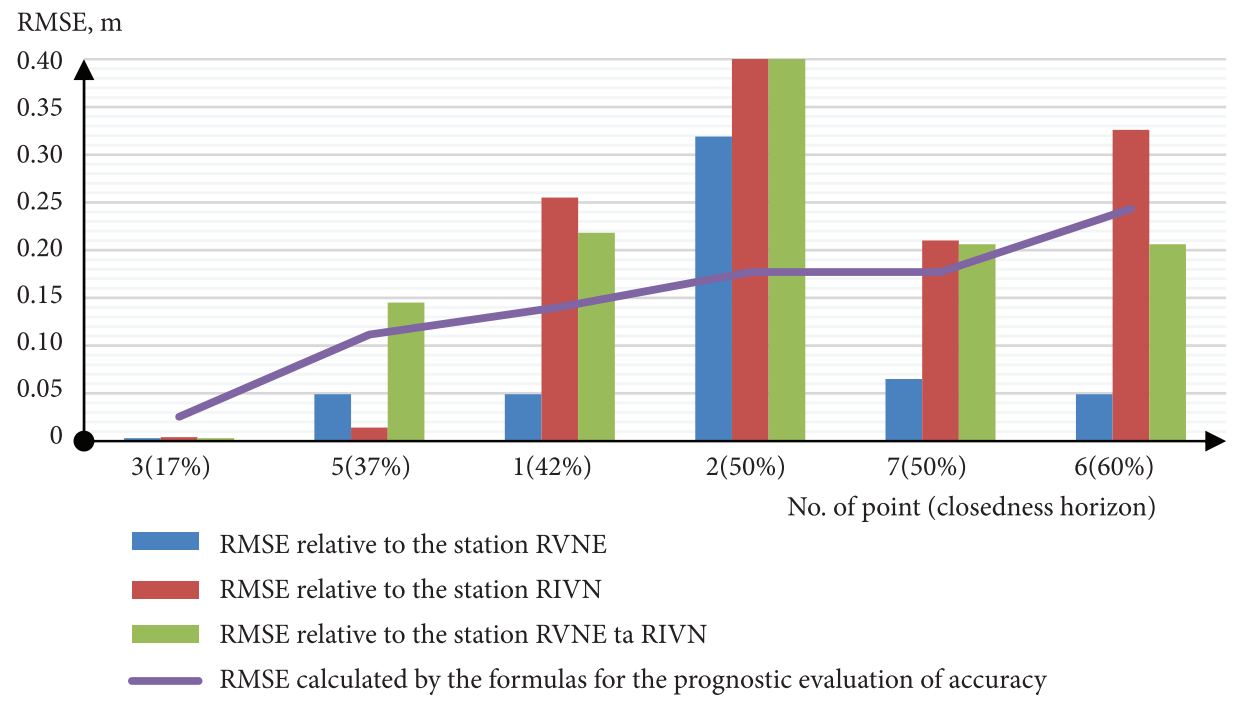

Figure 7. Comparison of RMSE of the planed location by the session duration for 1 hour and prognostic points of accuracy evaluation calculated by Equation (11) 


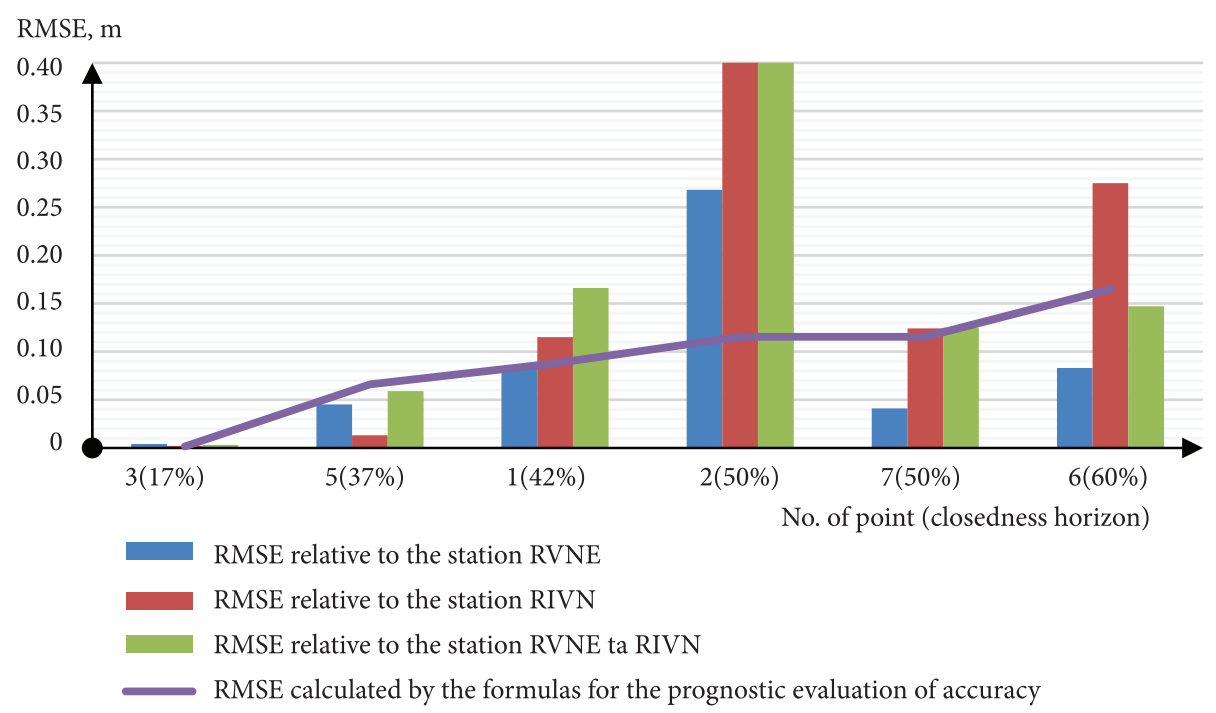

Figure 8. Comparison of RMSE of the height location by the session duration for 1 hour and prognostic points of accuracy evaluation calculated by Equation (12)

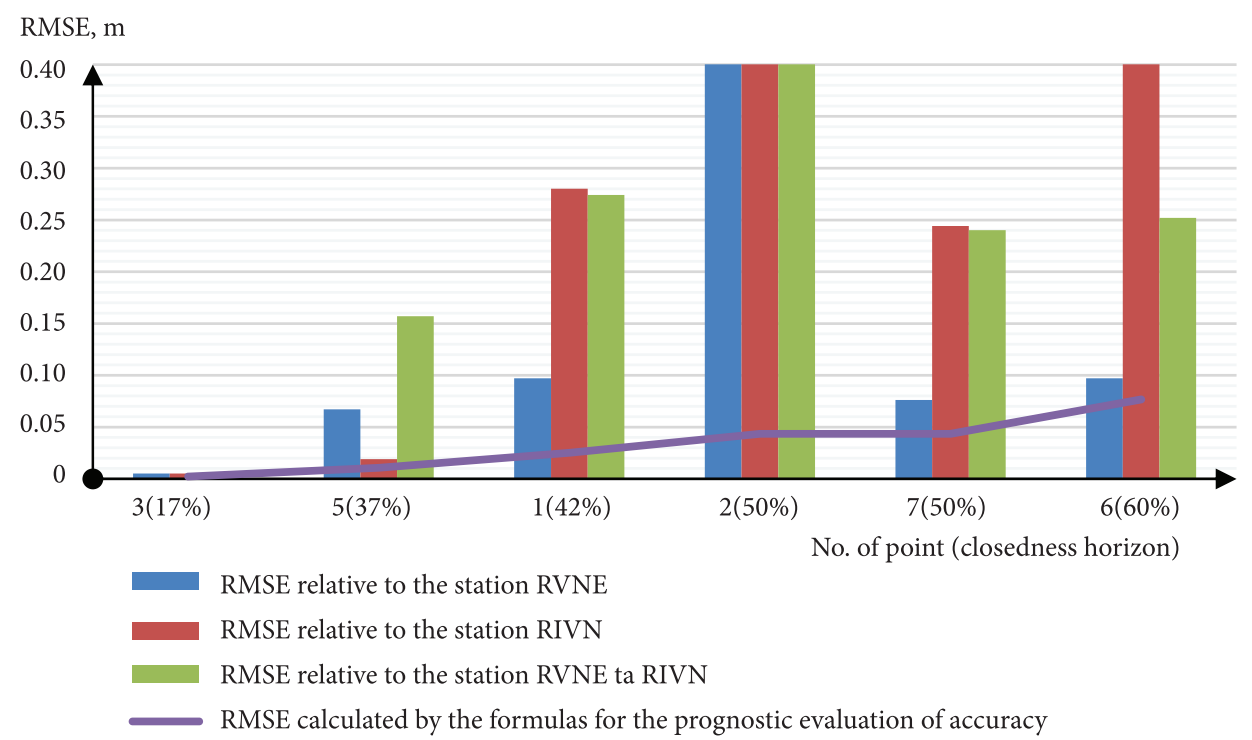

Figure 9. Comparison of RMSE of the spatial location by the session duration for 1 hour and prognostic points of accuracy evaluation calculated by Equation (13)

The regression analysis of received results has been executed. Also, the clarified regression equations in order to calculate the RMSE of spatial, planned, and height locations for the final point of the base line concerning the initial point have been received.

The represented equations allow executing the prognostic evaluation of observation accuracy of satellite investigations, which are based on the data about available obstacles. The provided dependencies have been received for the sessions with the following criteria, i.e. with the duration of observation for 1 hour, with the length of vectors for nearly $4 \mathrm{~km}$, and with the coefficient value of openness in between 5.17 to 10.31 . For further, it is necessary to expand the investigated vectors' length and the duration of observation sessions, as well as to determine the dependency for the receivers, which are able to simultaneously work with the GPS and GNSS systems.

\section{References}

Antonovich, K. (2005). Ispolzovanie sputnikovyh radionavigacionnyh sistem v geodezii (T. 1). Kartheotsentr (in Russian).

Baran, P., \& Chornokin, V. (2004). Vyznachennia tryvalosti GPSsposterezhen $\mathrm{v}$ geodezychnykh merezhakh. Visnyk geodezii ta kartohrafii, 2, 12-15 (in Ukrainian).

Bida, O. (2015). Osnovni dzherela pohybok vyznachennya koordynat punktiv suputnykovymy tehnologiyamy GNSS u rezhymi realnogo chasu. Visnyk Lvivskogo nacionalnogo agrarnogo universytetu, seriya: ekonomika APK, 22(2), 166-169 (in Ukrainian).

Chernyaga, P., \& Yanchuk, O. (2012). Poryadok vyznachennya prydatnosti punktu do GPS-sposterezhen. Suchasni dosiahnennya geodezychnoi nauky i vyrobnytstva, 1(23), 53-56 (in Ukrainian).

Dai, L., Wang, J., Rizos, C., \& Han, S. (2002). Pseudo-satellite applications in deformation monitoring. GPS Solutions, 5(3), 80-87. https://doi.org/10.1007/PL00012902 
Fouque, C., \& Bonnifait, P. (2010). Vehicle localization in urban canyons using geo-referenced data and few GNSS satellites. Retrieved February 05, 2019, from http://hal.archives-ouvertes. fr/docs/00/44/52/68/PDF/article-final.pdf

Gritsyuk, T., \& Tretyak, K. (2007). Do pytannya otsinki tochnosti vymiryuvannya perevischen metodom GPS. Geodeziya, kartografiya ta aerofotoznimannya, 69, 78-82 (in Ukrainian).

Kijewski-Correa, T., \& Kareem, A. (2003). The height of precision. GPS World, 14(9), 20-34.

Kostetska, Y., Toropa, I., \& Fok, O. (2005). Do pytannya tryvalosti GPS-sposterezhen zalezhno vid dovzhyny vectora-bazy. Suchasni dosyagnennya geodezychnoi nauky i vyrobnytstva, 2(10), 60-65 (in Ukrainian).

Ohrimchuk, A., Chernyaga, P., \& Yanchuk, O. (2011). Otsinka tochnosti viznachennya skladovykh vektoriv zalezhno vid tryvalosti GPS-sposterezhen ta obmezhennya vydymosti neboskhilu. Geodeziya, kartografiya ta aerofotoznimannya, 75, 17-25 (in Ukrainian).
Tretyak, K., \& Shushkova, T. (2001). Do pytannya tryvalosti GPS-vymiriv pry pobudovi derzhavnyh merezh 1-go ta 2-go klasiv. Geodeziya, kartografiya ta aerofotoznimannya, 61, 124-132 (in Ukrainian).

Tretyak, K. (2004). Optymizatsiya kinematichnyh geodesychnyh merezh (avtoref. dys. dokt. tekhn. nauk.). Natsionalnyi un-t "Lvivska politekhnika", Lviv, Ukraina (in Ukrainian).

Santerre, R., \& Boulianne, M. (1995). New tools for urban GPS surveyors. GPS World, 6(2), 49-54.

Yanchuk, O. (2010). Doslidzhennya tochnosti GPS-sposterezhen $\mathrm{v}$ ymovah obmezhenoii vydymosti horizontu. Inzhenerna geodeziya, 55, 224-235 (in Ukrainian).

Yanchuk, O., Shulgan, R., Dets, T., \& Struk, S. (2017). Evaluation of GPS observations accuracy within limited visibility basing on empiric data. Geodesy and Cartography, 43(3), 105-110. https://doi.org/10.3846/20296991.2017.1371648 